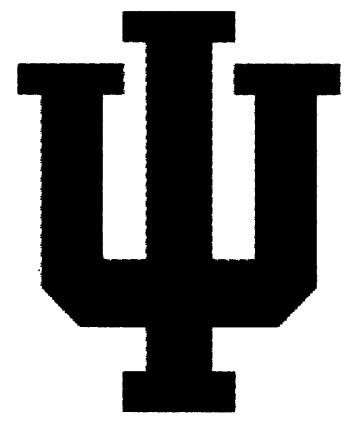

Indiana Health Law Review

\title{
Heather Harrell
}

Heather Harrell received her BA from Columbia College of Columbia University and her MD from Baylor College of Medicine. She completed a fellowship in Bioethics at the University of Louisville's Institute for Bioethics, Health Policy and Law before obtaining her JD from Northwestern University. 



\title{
Direct-to-Consumer AdVertising of Prescription \\ PHARMACEUTICALS, THE LEARNED INTERMEDIARY DOCTRINE, AND FIDUCIARY DUTIES
}

\author{
Heather Harrell*
}

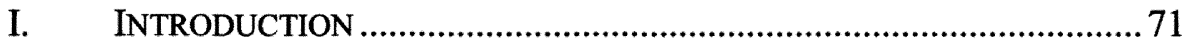

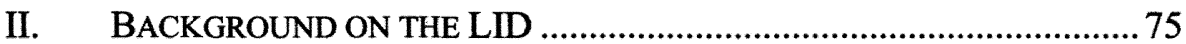

III. DTC ADVERTISING WARRANTS A GENERAL OR CASE-BY-CASE

EXCEPTION TO THE LID, ESPECIALLY GIVEN RECENT CHANGES

TO THE HEALTH CARE SYSTEM .................................................... 78

IV. DRUG PROMOTION TO THE PHYSICIAN PROVIDES FURTHER

SUPPORT FOR A GENERAL OR CASE-BY-CASE EXCEPTION TO

THE LID

V. DTC ADVERTISING CREATES A NEAR OR ACTUAL FIDUCIARY

RELATIONSHIP BETWEEN PATIENT AND PHARMACEUTICAL

MANUFACTURER

VI. CONCLUSION

\section{INTRODUCTION}

Advertisements for prescription medications have become ubiquitous. ${ }^{1}$ It is nearly impossible to watch thirty minutes of television without seeing at least one, if not several, advertisements for medications treating such conditions as erectile dysfunction, insomnia, high cholesterol, or overactive bladder. Pharmaceutical manufacturers rely on more than just television to spread the word about their products; manufacturers also rely on magazines, newspapers, and interactive websites.

The seeming bombardment of the public by promotion of prescription pharmaceuticals is truly a barrage on the public by the pharmaceutical industry as evidenced by the amount spent on drug advertising. In 2005, spending on direct-to-consumer ("DTC") advertising was over $\$ 4.23$ billion, ${ }^{2}$ and total spending on drug promotion was approximately $\$ 29.9$ billion. ${ }^{3}$ Advertising, both directly to the patient as well as to the physician,

* BA, Columbia College, Columbia University, 1999. MD, Baylor College of Medicine, 2004. JD, Northwestern University School of Law, 2008. I would like to thank all of those who read and commented on this article, especially Mark Rothstein. Sincere thanks to my family for their continued support.

1. Andrew R. Robinson, et al., Direct-to-Consumer Pharmaceutical Advertising: Physician and Public Opinion and Potential Effects on the Physician-Patient Relationship, 164 ARCHIVES INTERNAL MED. 427, 431 (2004) (noting that $99.2 \%$ of the public reported seeing at least one DTC advertisement).

2. Julie M. Donahue, Marisa Cevasco \& Meredith B. Rosenthal, A Decade of Directto-Consumer Advertising of Prescription Drugs, 357 NEW ENG. J. MED. 673, 676 (2007).

3. Id. at 676 . The percentage of sales spent on drug promotion has increased from 
works - one review found that for each dollar spent on promotion, prescription sales increased $\$ 2.20 .^{4}$ These figures raise concerns that this increase in prescription drug sales may represent overuse of these drugs or overuse of the more expensive, advertised drug in lieu of a cheaper, equally effective alternative. $^{5}$

Though the amount spent on drug promotion may be concerning in and of itself, the content of some DTC advertisements raises further issues. Many advertisements, for all practical purposes, recommend the medication for those individuals with certain symptoms. Some companies have set up on-line quizzes to assess the need for a particular medication, ${ }^{6}$ with the pharmaceutical manufacturer usually giving feedback on the quiz to the prospective patient. ${ }^{7}$ Although these individuals are instructed to share the quiz results with their physicians, ${ }^{8}$ the results and, sometimes, physiciandirected information about the results, are available to the potential consumer of the drug. ${ }^{9}$ In addition to interactive and advisory internet advertising, individuals can download free trial coupons for prescription medications ${ }^{10}$ or apply for financial assistance from the drug company for their prescriptions. ${ }^{11}$ In other words, advertisements may do more than mention a drug and its indications; advertisements are offering incentives and advice that may be based on individualized information. Such advertisements are likely to influence prescription-seeking behavior and should not be legally unchecked.

Advertising of prescription pharmaceuticals is regulated by the Food and Drug Administration ("FDA"). Changes to FDA regulations in 1997, allowed for the burgeoning of DTC advertising. ${ }^{12}$ Concomitant with the increase in DTC advertising, there has been a decrease in the number of FDA letters sent to pharmaceutical manufacturers regarding violations of the DTC advertising regulations. ${ }^{13}$ While some have interpreted these facts to demonstrate increased compliance with the regulations, ${ }^{14}$ others feel the FDA is overwhelmed and has insufficient manpower and systems in place

14.2 to $18.2 \%$ between 1996 and 2005. Id. at 675 .

4. U.S. Gov'T ACCOUNTABILITY OfFICE, GAO-07-54, Prescription Drugs: IMPROVEMENTS NEEDED IN FDA'S OVERSIGHT OF DIRECT-TO-CONSUMER ADVERTISING (2006) [hereinafter GAO-07-54], available at $\mathrm{http} / / / \mathrm{www} . g a 0 . g o v / n e w . i t e m s / d 0754$.pdf.

5. Donahue et al., supra note 2, at 674.

6. See, e.g., OAB Symptom Quiz, PFizer INC. (Dec. 29, 2009), http://www.detrolla .com/OABSymptomQuiz.aspx?PrinterFriendly=TRUE.

7. See, e.g., id.

8. See, e.g., id.

9. See, e.g., id.

10. See, e.g., Special Toviaz Offers, PFIZER, INC. (Nov. 4, 2010), http://www.toviaz .com/offers.aspx.

11. See, e.g., id.

12. See, e.g., Donahue et al., supra note 2, at 674; Daniel Richardson, The Lost Child of Products Liability: New Thoughts About Advertising and the Learned Intermediary Doctrine, 27 VT. L.REV. 1017, 1033 (2003).

13. GAO-07-54, supra note 4, at 21.

14. Donahue et al., supra note 2, at 679. 
to provide proper oversight. ${ }^{15}$ In support of the latter contention, the United States Government Accountability Office found significant limitations to FDA regulation of DTC advertising in two separate reports. ${ }^{16}$ These regulatory limitations, however, do not leave the consumer without recourse.

The tort system indirectly and retrospectively supplements FDA regulation of DTC advertising by providing relief to those who have been injured by an advertised drug. ${ }^{17}$ Under product liabilities law, the main claims that can be pursued by injured individuals are manufacturing defect, design defect, or failure to warn. ${ }^{18}$ However, only failure to warn claims relate to DTC advertising and these claims are effectively barred in many jurisdictions by the learned intermediary doctrine ("LID"). ${ }^{19}$ The LID essentially states that, because a patient must receive a prescription from a physician, the manufacturer of prescription medication has fulfilled its duty to warn by warning the physician. ${ }^{20}$ In other words, the physician remains liable to the patient for failing to share the medication's risks, but the pharmaceutical manufacturer does not. ${ }^{21}$ Hence, the tort system is, in many jurisdictions, limited in its ability to supplement the FDA's regulation of DTC advertising.

Exceptions to the LID do exist and are usually applied when circumstances have changed the patient-physician relationship. An exception has been applied for DTC advertising in some jurisdictions. ${ }^{22}$ When an exception to the LID is applicable, the manufacturer of the prescription drug is responsible for warning the ultimate consumer.

This Article examines some recent data about the effects of DTC advertising on the patient-physician relationship in support of the notion that DTC advertising warrants an exception to the LID. Prescription drugs are also promoted to physicians. Hence, drug advertising encroaches upon the fiduciary patient-physician relationship not from one, but from two sides. Not only should the law protect the patient-physician relationship by dis-

15. See, e.g., id.; GAO-07-54, supra note 4, at 19 (mentioning that the FDA does not have the manpower to review all of the advertisements it receives).

16. See GAO-07-54, supra note 4; U.S. Gov'T ACCOUNTING OFFICE, GAO-03-177, PRESCRIPTION DRUGS: FDA OVERSIGHT OF DIRECT-TO-CONSUMER ADVERTISING HAS LIMITATIONS (2002), available at http://www.gao.gov/new.items/d03177.pdf.

17. See generally RESTATEMENT (THIRD) OF TORTS: PRODUCTS LIABILITY $\S 6$ (1998).

18. Id.

19. Larkin v. Pfizer, Inc., 153 S.W.3d 758, 767 (Ky. 2004) (finding thirty-four states had officially adopted the LID); Vitanza v. Upjohn, 778 A.2d 829, 838 (Conn. 2001) (finding forty-four jurisdictions had adopted the LID).

20. See, e.g., Vitanza, 778 A.2d at 832.

21. However, it is important to note that the manufacturer could be held liable even in jurisdictions where the LID is applied if it is found that the drug maker inadequately warned the physician. Ackerman v. Wyeth Pharm., 526 F.3d 203, 208 (5th Cir. 2008).

22. See, e.g., Perez v. Wyeth Lab. Inc., 734 A.2d 1245, 1247 (N.J. 1999) (stating that "a pharmaceutical manufacturer that makes direct claims to consumers for the efficacy of its product should not be unqualifiedly relieved of a duty to provide proper warnings of the dangers or side effects of the product."). 
couraging such intrusion into a fiduciary relationship, but drug promotion raises the question of whether a physician can function as a true "learned intermediary" in such an environment. This Article outlines the criteria for a true "learned intermediary" as can be deduced from the case law. This Article also suggests that the question of whether a physician fulfilled the criteria that justifies application of the LID be considered on a case-by-case basis. Research is used to demonstrate how drug promotion makes it difficult, if not impossible, for the physician to function as a true "learned intermediary." In other words, this Article argues that a general exception to the LID is justified: 1) by traditional considerations given recent research on the effect of DTC advertising on patient-physician relationships; 2) because DTC advertising makes it difficult for a physician to fulfill the criteria of a "learned intermediary;" and 3) because the law should protect fiduciary relationships, especially when that relationship is weakened by influence exerted over both doctors and their patients. If a general exception for DTC is not accepted or not deemed applicable, courts should consider in each case whether the physician met the criteria of a true "learned intermediary."

This Article further argues that the content of pharmaceutical advertisements and websites has placed prescription drug manufacturers, at least some of the time, in a near or actual fiduciary role with respect to the ultimate consumer of their prescription medications. Given the responsibility that comes with being a fiduciary, it is untenable to insulate the drug maker through the LID from liability for their advertisements. By opening up liability through the elimination of the LID when DTC advertising has occurred or, at the very least, considering whether the physician functioned as a true "learned intermediary" in cases where an exception to the LID is not applied, products liability claims may successfully supplement FDA regulation of DTC advertising.

Section II of this Article provides background information on the LID and describes the characteristics of a "learned intermediary" as can be drawn from the case law. In section III, this Article argues that the rationale for exceptions to the LID is applicable when DTC advertising has occurred and the reasoning may be even more poignant given certain recent changes to our health care system. Section III also demonstrates how DTC impedes a physician's ability to serve as a true "learned intermediary". Section IV discusses how a legally recognized fiduciary relationship, the doctor-patient relationship, is weakened by both DTC and direct-to-physician advertising. This two-sided invasion of a fiduciary relationship provides additional support for creating an exception to the LID for DTC advertising. This section additionally demonstrates how direct-to-physician advertising may make it impossible for a physician to function as a true "learned intermediary." Section V demonstrates how pharmaceutical manufacturers, through the content of their advertisements, place themselves in a near or actual fiduciary role with respect to the ultimate consumer of their drugs. The final sec- 
tion concludes with possible solutions to the current state of the LID.

\section{BACKGROUND ON THE LID}

The tort system, mostly through failure to warn claims, provides some retrospective regulation of DTC marketing. Comment $\mathrm{k}$ of the Restatement (Second) of Torts addresses the need to provide "proper warning" for unavoidably unsafe products, such as prescription pharmaceuticals. ${ }^{23}$ While some courts interpret the lack of a proper warning to leave the manufacturer strictly liable to the injured plaintiff, others recognize that the examination of a warning's propriety follows the logic of a negligence analysis. ${ }^{24} \mathrm{Re}-$ gardless, even for unavoidably unsafe products, a "proper warning" is required. The persistent question with regards to prescription drugs, a question without a consistent answer, is to whom the warning must be given.

As noted in the introduction of this Article, many jurisdictions have adopted the LID, a doctrine which designates the physician as the appropriate recipient of warnings about prescription drugs. In fact, one court noted that, as of 2004, thirty-four states had officially adopted the LID, while even more had adopted the doctrine indirectly. ${ }^{25}$ However, another court claimed that, as of 2007, only twenty-two states had expressly adopted the LID by statute or higher court. ${ }^{26}$ Though not accepted in all jurisdictions, the LID has become a fairly well-established exception to the general rule that manufacturers must warn the actual consumer of their product's risks. ${ }^{27}$

Courts provide different justifications for their adoption of the LID. Many of the justifications involve preservation of the patient-physician relationship. ${ }^{28}$ While not providing much detail, some courts have stated that the physician is the best person to warn the patient. ${ }^{29}$ Presumably, these courts believe that the physician can personally determine whether the patient understands the warning, because they have stated that consumers would have difficulty comprehending medication warnings without the assistance of their doctor. ${ }^{30}$ In addition, a physician can provide an independ-

23. Restatement (SECOND) OF TORTS $\S 402 \mathrm{~A} \mathrm{cmt.} \mathrm{k}$ (1977).

24. See Hahn v. Richter, 628 A.2d 860, 867 (Pa. Super. Ct. 1993) (citing Harford Mutual Ins. v. Moorhead, 578 A.2d 492 (Pa. Super. Ct. 1990)).

25. Larkin v. Pfizer, Inc., 153 S.W.3d 758, 767 (Ky. 2004).

26. West Virginia ex rel. Johnson \& Johnson Corp. v. Karl, 647 S.E.2d 899, 905 (W. Va. 2007).

27. See Perez v. Wyeth Lab. Inc., 734 A.2d 1245, 1255 (N.J. 1999) (discussing the general rule that manufacturers must warn foreseeable, ultimate consumers about their products).

28. See, e.g., id (relaying that one of the "theoretical bases" for the LID is a "reluctance to undermine the doctor patient relationship").

29. See, e.g., Larkin, 153 S.W.3d at 763; see, e.g., Vitanza v. Upjohn, 778 A.2d 829, 837 (Conn. 2001).

30. Mendez Montes de Oca v. Aventis, 579 F. Supp.2d 222, 227-28 (D. Puerto Rico, 
ent medical judgment about the appropriateness of a particular drug for the individual patient. ${ }^{31}$ Courts have adopted the LID to prevent interference with these and other aspects of the patient-physician relationship. ${ }^{32}$ For instance, warnings provided by the drug manufacturer may be different than those provided by the doctor, thereby undermining the trust necessary for a successful patient-physician relationship. ${ }^{33}$ Another possibility is that the manufacturer's warnings may frighten the consumer to the point that he or she decides not to take life-saving or life-prolonging medication. ${ }^{34}$ Beyond concerns about the patient-physician relationship, courts, in support of the LID, have stated that manufacturers lack an effective way to communicate with the ultimate consumers of their product. ${ }^{35}$

Jurisdictions also vary in their application of exceptions to the LID. Some of the most commonly recognized exceptions include mass immunizations and contraceptives. ${ }^{36}$ In these cases, one of the basic premises for the application of the LID is missing - the dialogue between physician and patient is limited or perhaps even non-existent in the decision to take the medication. $^{37}$ Another, less uniformly applied, exception to the LID occurs when the FDA requires a direct warning to the patient about medications or devices. ${ }^{38}$ Here again, it is presumed that the physician plays less of a role when the manufacturer must directly communicate with the consumer. In considering the exceptions to the LID, one court decided not to adopt the LID because too many exceptions would simultaneously have to be adopted to "justly utilize[]" the doctrine." In sum, the exceptions to the LID vary greatly among jurisdictions.

The common law landscape of the LID becomes even more complicated when considering the judicial response to drug promotion. At least

2008); Johnson \& Johnson Corp., 647 S.E.2d at 905 n. 9.

31. Eck v. Parke, Davis \& Co., 256 F.3d 1013, 1018 (10th Cir. 2001) (quoting Edwards v. Basel Pharm., 933 P.2d 298, 300 (Ohio 2008), and emphasizing the requirement that a physician "exercise independent judgment" in prescribing medication).

32. See, e.g., Perez, 734 A.2d at 1255 (providing as the first theoretical basis for the LID that "courts do not wish to intrude upon the doctor-patient relationship").

33. See, e.g., id.

34. See, e.g., Larkin, 153 S.W.3d at 764.

35. See, e.g., id.

36. See, e.g., West Virginia ex rel. Johnson \& Johnson v. Karl, 647 S.E.2d 899, 911 (W.V. 2007). But see In re Norplant, 165 F.3d 374 (5th Cir. 1999) (finding LID applicable to cases involving implantable contraceptive device).

37. See, e.g., Jeffrey J. Wiseman, Another Factor in the "Decisional Calculus": The Learned Intermediary Doctrine, The Physician-Patient Relationship, and Direct-toConsumer Marketing, 52 S.C. L. Rev. 993, 1005 (2001) (relating that patients at mass immunizations do not receive individualized attention from a physician); MacDonald v. Ortho Pharmaceutical Corp., 475 N.E.2d 65, 69 (Mass. 1985) (stating that consumers of contraceptives are much more involved in the decision to use the medication, the medication is used for the long-term even though the patient will only interact with the physician on an annual basis, and that it is difficult for the physician to cover all of the risks and benefits of the contraceptive medication in an annual exam).

38. Edwards v. Basel Pharm., 933 P.2d 298, 301 (Okla. 1997).

39. Johnson \& Johnson, 647 S.E.2d at 913. 
one court has allowed an exception to the LID for "overpromotion" of a drug to physicians. ${ }^{40}$ With respect to DTC advertising, several courts have applied the LID even when drug promotion played a role in the case. ${ }^{41}$ In contrast, the New Jersey Supreme Court expressly created an exception to the LID when the pharmaceutical manufacturer has advertised directly to the public. ${ }^{42}$ To confuse the matter further, another court declined to adopt the LID in part because the first court to suggest the doctrine partially relied on the fact that no representations had been made directly to the public about the drug. ${ }^{43}$

Most courts assume that the prescribing physician functions as a learned intermediary when no general exception is applicable. However, courts should consider if the physician actually did function as a "learned intermediary" in each case where no general exception to the LID exists, rather than rely on an assumption that is open to interpretation. Judicial opinions generally do not list the characteristics of a true "learned intermediary;" nevertheless, by looking to judicial reasoning in deciding to accept, reject, or create exceptions to the LID, one can decipher certain criteria that a physician must have in order to function as a "learned intermediary." These criteria are as follows: 1) a patient-physician relationship must exist $^{44}$ 2) the physician must know the characteristics of the prescribed medication; ${ }^{45}$ ) the physician must know the patient's current medical status and medical history; ${ }^{46}$ ) the physician must make an independent medical

40. Brown v. Glaxo, Inc., 790 So.2d 35, 40 (La. Ct. App., 2001) (finding that verbal representations about medication, made to pharmacists and physicians, could override the written warnings to the physicians, thereby allowing for an exception to the LID).

41. See, e.g., In re Meridia, 328 F.Supp.2d 791, 811-12 (N.D. Ohio 2004) (stating that most states have not applied an exception to LID in face of DTC, and, therefore, a federal court is limited by the decisions of those states); In re Norplant, 165 F.3d at 379 (finding that Texas law applied the LID wherever a physician-patient relationship existed, regardless of the presence of DTC advertising); Hackett v. G.D. Searle \& Co., 246 F.Supp.2d 591 (W.D. Tex. 2002) (finding that LID applies even when DTC applies).

42. Perez v. Wyeth Laboratories Inc., 734 A.2d 1245, 1247 (N.J. 1999) (stating that "a pharmaceutical manufacturer that makes direct claims to consumers for the efficacy of its product should not be unqualifiedly relieved of a duty to provide proper warnings of the dangers or side effects of the product.").

43. Johnson \& Johnson, 647 S.E.2d at 907 (stating that "[t]he Marcus court clearly found significance in the fact that no representations had been made directly to the plaintiff').

44. See, e.g., In re Norplant, 165 F.3d at 379 (stating that "as long a physician-patient relationship exists, the learned intermediary doctrine applies.").

45. See, e.g., Johnson \& Johnson, 647 S.E.2d at 905 (quoting Terhune v. A.H. Robins Co., 577 P.2d 975, 978 (Wash. 1978) as saying of the physician, "[i]t is his duty to inform himself of the qualities and characteristics of those products which he prescribes for or administers to or uses on his patients."); Vaccariello v. Smith \& Nephew Richards, Inc., 763 N.E.2d 160, 164 (Ohio 2002) (quoting themselves in Tracy v. Merrell Dow Pharm., Inc., 569 N.E.2d 875, 878 (Ohio 1991) as stating that it is the physician's "duty to know . . the qualities and characteristics of the drugs or products to be prescribed.").

46. See, e.g., Vaccariello, 763 N.E.2d at 164 (quoting themselves in Tracy, 569 N.E.2d at 878 as stating that it is the physician's "duty to know the patient's condition.") and Ma- 
judgment in choosing to prescribe the drug; ${ }^{47}$ ) the physician must play a meaningful and significant role in prescribing the medication and evaluating the patient ${ }^{48} 6$ ) the physician should be the sole source, or at the very least the primary source, of information about the disease and drug ${ }^{49}$ and 7) the physician must be in a position to reduce the risks of harm from the drug. ${ }^{50}$ Drug promotion affects a physician's ability to fulfill some of these criteria. Hence, these criteria could provide further support for a general exception to the LID for DTC advertising, or could be used on a case-bycase basis to determine if the physician functioned as a true "learned intermediary," making it possible to apply the LID.

\section{DTC ADVERTISING WARRANTS A GENERAL OR CASE-BY-CASE EXCEPTION TO THE LID, ESPECIALLY GIVEN RECENT CHANGES TO THE HEALTH CARE SYSTEM}

Exceptions to the LID are frequently applied when the original justifications are absent, most notably when there has been an erosion of the patient-physician relationship ${ }^{51}$ such that relying solely on the physician to provide the warnings is inappropriate, impossible, or naïve. In addition, the LID cannot be applicable when there is no true "learned intermediary" as defined by the criteria gleamed from case law. Using recent data, this section of the Article explores how drug promotion alters the patient-physician relationship and makes it difficult for a physician to meet the criteria of a

kripodis v. Merrell-Dow Pharm., Inc., 523 A.2d 374, 378 (Pa. Super. Ct. 1987) (quoting Leibowitz v. Ortho Pharm. Corp., 307 A.2d 449, 457 (Pa. Super. Ct. 1973) as saying that the physician must use the "personal medical history of the patient" to determine if a drug should be prescribed).

47. See Johnson \& Johnson, 647 S.E.2d at 905 (quoting Terhune, 577 P.2d at 978 as saying that the physician must "exercise an independent judgment") and Makripodis, 523 A.2d at 378 (quoting Leibowitz, 307 A.2d at 457 as saying that the physician should "use his independent medical judgment").

48. See, e.g., In re Norplant, $165 \mathrm{~F} .3 \mathrm{~d}$ at 379 (giving the fact "that physicians play a significant role in prescribing Norplant" as one reason to apply the LID); MacDonald v. Ortho Pharm. Corp., 475 N.E.2d 65, 69 (Mass. 1985) (explaining that annual interaction between patient and physician for birth control prescriptions is not frequent enough, given other factors, to apply the LID); and Perez v. Wyeth Laboratories Inc., 734 A.2d 1245, 1255 (N.J. 1999) (suggesting that meaningful interaction between patient and physician is required to apply the LID when stating that "because managed care has reduced the time allotted per patient, physicians have considerably less time to inform patients of the risks and benefits of a drug.").

49. See Johnson \& Johnson, 647 S.E.2d at 905 (quoting Terhune, 577 P.2d at 978 as saying "[t]he physician decides what facts should be told to the patient.") and McKee v. American Home Products Corp., 782 P.2d 1045 (Wash. 1989) (finding pharmacist has no duty to warn of risks of prescription drug and citing to several cases implying the LID is applicable because the physician is the sole or primary source of information).

50. See, e.g., Vitanza v. Upjohn, 778 A.2d 829, 841 (Conn. 2001) (stating "the prescribing physician of a prescription drug is the person best able to take or recommend precautions against the [potential] harm.").

51. See, e.g., Perez, 734 A.2d at 1255-56. 
"learned intermediary." Changes to the patient-physician relationship that have occurred independent of, but at the same time as, increasing drug promotion are also evaluated. These changes affect both the way in which drug promotion alters patient-physician encounters and the back drop against which the LID is justified. The data will demonstrate that the presence of DTC advertising in the modern healthcare system supports application of an exception to the LID.

Prescription drugs can be divided into therapeutic and nontherapeutic, ${ }^{52}$ or lifestyle and medically necessary drugs. ${ }^{53}$ The basic idea behind this division is that patients play a larger role and physicians a smaller role in decisions regarding medications that are not medically necessary or lifesaving, ${ }^{54}$ thereby weakening the rationale for the LID. $^{55}$ The smaller the role played by the physician in a particular instance, the less likely the physician will fulfill the "learned intermediary" criteria of playing a meaningful or significant role in prescribing and evaluating the patient. In other words, the prescription of lifestyle drugs generally weakens the reasoning used to apply the LID in all cases, but may also make the LID inapplicable in certain cases where the physician no longer meets the definition of a "learned intermediary."

The Restatement (Second) of Torts implies, and has been interpreted by some courts to mean, that the exception to strict liability for unavoidably unsafe products rests on the idea that these medications "possess[] such a high degree of social need." "56 Thus, by inference, manufacturers of purely lifestyle drugs could be considered subject to strict liability, regardless of the warning content or to whom it was directed. Many of the drugs that are advertised directly to the consumer could be considered "lifestyle" medications. ${ }^{57}$ In addition, a large percentage of advertised pharmaceuticals treat chronic conditions; ${ }^{58}$ these drugs affect long-term health outcomes that may also be altered by other lifestyle factors. ${ }^{59}$ It is difficult to say if these drugs

52. Wiseman, supra note 37 , at 1010.

53. Perez, 734 A.2d at 1257.

54. See Wiseman, supra note 37 , at 1010 .

55. See Richardson, supra note 12, at 1028-29 (explaining that the insulation from liability by the LID is justified, in part, by the importance of their products to saving lives).

56. Hill v. Searle, 884 F.2d 1064, 1068 (8th. Cir. 1989); see also RESTATEMENT (SECOND) OF TORTS, $\S 402 \mathrm{~A} \mathrm{cmt.} \mathrm{k} \mathrm{(1977)} \mathrm{(mentioning} \mathrm{the} \mathrm{rabies} \mathrm{vaccine} \mathrm{as} \mathrm{an} \mathrm{example} \mathrm{of}$ unavoidably unsafe products and finding that the serious risks of the vaccine are justified by the horrible consequences of the disease).

57. For instance, advertisements for erectile dysfunction are common, as well as advertisements for medications meant to enhance looks, such as Latisse.

58. Donahue, supra note 2, at 676.

59. For example, a person's cholesterol may also be lowered with diet and exercise and a person's blood pressure may be lowered through weight loss. J.S. Lin et al., Behavioral Counseling to Promote Physical Activity and a Healthful Diet to Prevent Cardiovascular Disease in Adults: A Systematic Review for the U.S. Preventive Services Task Force, 153 ANNALS OF INTERNAL MED. 736 (2010) (finding small reductions in cholesterol levels with more healthful diet and increased exercise) and M.L. Tuck et al., The Effect of Weight Re- 
would be considered medically necessary or some other intermediate category.

Regardless of how the advertised medication is classified, DTC advertising and patient and physician views about such advertising affect many patient-physician interactions. The majority of the public have generally negative views of DTC promotion of prescription pharmaceuticals, ${ }^{60}$ with just over a quarter of the public feeling DTC advertising makes them more informed about their health conditions, ${ }^{61}$ and slightly over ten percent believing DTC advertising motivates care-seeking behavior. ${ }^{62}$ Physicians generally have concerns about the possibly incomplete and biased information that may be presented in such advertisements, ${ }^{63}$ although more than forty percent of physicians surveyed felt that DTC advertising helped better inform their patients about their health problems. ${ }^{64}$ Furthermore, more than half of physicians felt DTC advertising can encourage individuals to seek medical care. ${ }^{65}$ Most importantly, more than half of physicians felt that DTC advertising has led to specific medication requests and changed patient expectations of them; ${ }^{66}$ between ten and fifteen percent of the public reported that DTC advertising had led to specific medication requests or changed their expectations of their physicians. ${ }^{67}$

It has been found that between eighteen and forty-four percent of individuals who see DTC advertising discuss either the advertised drug or the condition with their doctor, with about twenty-five percent of those discussions including a request for the advertised medication. ${ }^{68}$ In those cases where a medication is discussed as a result of DTC advertising, the physician is not the sole source, and may not even be the primary source, of information about the medical condition or treatment. The physician, in those cases, might not meet the definition of "learned intermediary" as outlined by the common law.

Most doctors do believe that DTC advertising encourages patients to talk about issues that they might not otherwise discuss. ${ }^{69}$ Some advertising goes beyond encouraging discussion of certain topics. For example, one company provided consumers with specific questions to ask and suggested

duction on Blood Pressure, Plasma Renin Activity, and Plasma Aldosterone Levels in Obese Patients, 304 NEW ENG. J. MED. 930 (1981) (finding a reduction in blood pressure with weight loss in obese patients).

60. Robinson et al., supra note 1 , at 431 .

61. Id. at 429 .

62. Id.

63. Id. at 428.

64. Id. at 429.

65. Id.

66. IId.

67. Id.

68. GAO-07-54, supra note 4.

69. Elizabeth Murray et al., Direct-to-Consumer Advertising: Physicians' Views of Its Effects on Quality of Care and the Doctor-Patient Relationship, 16 J. AM. BD. FAM. MED. 513,518 (2003). 
information the patient should share with his or her physician. ${ }^{70}$ In that case, the company was unabashedly trying to guide the patient-physician discussion by providing prompts and giving prospective consumers a chance to prepare answers for potential physician questions. In other words, DTC advertising alters many patient-physician encounters by influencing the topics and direction of discussion. Furthermore, in fewer than half of the conversations initiated by patients because of DTC advertising did the physician perceive that the patient wanted his or her opinion, rather the patient was understood to want a specific intervention. ${ }^{71}$

Almost half of individuals who participated in a particular survey reported they would be disappointed if a physician did not prescribe a requested medication, and a quarter would try to change the physician's opinion. $^{72}$ From a physician perspective, under a quarter of surveyed physicians admit that DTC advertising has affected their own prescribing practices. ${ }^{73}$ However, "patient demand is the most commonly offered physician explanation for inappropriate prescribing."74 More than seventy percent of patients who request a drug that they have seen advertised receive a prescription for that medication, even though fifty percent of these prescriptions were deemed inappropriate. ${ }^{75}$ In other words, DTC advertising affects the patient-physician relationship by altering treatment outcomes, and may invalidate the application of the LID since the physician is not making an independent medical judgment, as required by the common law criteria of a "learned intermediary."

One study found the public felt DTC advertising had less influence on

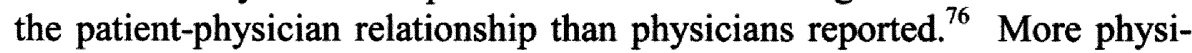
cians felt that DTC advertising had a positive effect on the patient-physician relationship than a negative effect; those physicians reporting a positive effect tended to have more clinically appropriate patient inquiries, doctor compliance with patient requests, and a sense that the patient was taking responsibility for his or her own health. ${ }^{77}$ On the other hand, the relationship was perceived as being negatively affected by DTC advertising when the advertisement led to requests or information that the doctor felt was in-

70. Preparing for Your VIAGRA Talk: What to Ask Your Doctor, PFIZER, INC. (Aug. 2010), http://www.viagra.com/viagra-prescription/viagra-questions.aspx; Preparing for Your VIAGRA Talk: What to Tell Your Doctor, PFIZER, INC. (Aug. 2010), http://www.viagra.com/ viagra-prescription/viagra-questions/what-to-tell-your-doctor.aspx.

71. Murray et al., supra note 69 , at 521 .

72. Robinson et al., supra note 1 , at 428.

73. Id. at 430

74. Id. at 431 .

75. Barbara Mintzes et al., How Does Direct-to-Consumer Advertising Affect Prescribing? A Survey in Primary Care Environments with and without Legal DTCA, 169 CAN. MED. Ass'N J. 405 (2003).

76. Robinson et al., supra note 1 , at 430.

77. Murray et al., supra note 69 , at 519. 
appropriate. $^{78}$ Therefore, when doctor and patient opinion differed, DTC advertisement was viewed as negatively affecting the relationship. Regardless of patient or physician views, there is little doubt that DTC advertising alters the patient-physician relationship the LID is meant to protect. DTC advertising changes the information the patient has with respect to treatment and condition, alters views on proper physician roles, influences the content of discussion, and can affect treatment decisions. In addition, DTC advertising may make it impossible for the physician to function as a true "learned intermediary" because it provides another influential source of information to the patient and influences the physician's judgment.

The rise in DTC advertising has occurred alongside many changes to the health care system, one of which is the increasing importance of the doctrine of informed consent. Informed consent allows a patient to intelligently exercise patient autonomy, even requiring respect for a patient's decision not to take a clearly lifesaving medication. ${ }^{79}$ The LID was more uniformly accepted and applied earlier than the doctrine of informed consent and was based on a world where paternalistic medicine was the norm. ${ }^{80}$ The widespread application of informed consent has altered the basic duties of the patient-physician relationship, placing more responsibility on the patient and less on the physician, and strikes at the most basic rationale for the LID. In fact, some courts have declined to apply the LID in part because informed consent heavily undermines the support for the doctrine. ${ }^{81}$ Yet, it is logical that the LID would apply if the physician is the sole source of information about the diagnosis and treatment and utilizes independent medical decision making in deciding what information to share with the patient. With DTC advertising, the physician is not the sole source of information and may be biased by DTC advertising in his or her decision making. In other words, the rise of informed consent alone may weaken, but not negate the rationale for the LID. However, when DTC advertising occurs against the backdrop of informed consent, the physician is no longer a true "learned intermediary." Since the patient makes the ultimate decision regarding treatment, it is conceivable that DTC advertising has more of an effect on prescription drug consumption currently, than if DTC promotion occurred in a world of paternalistic medicine.

In addition to the rise of informed consent, other changes to the prac-

78. Id.

79. See April L. Foreman, Web of Manipulation: The Learned Intermediary Doctrine and Direct-To-Consumer Advertising on the World Wide Web, 35 J. MARSHaLl L. REv. 97, 108-09 (2001) (noting increased "patient autonomy"); Perez v. Wyeth Laboratories Inc., 734 A.2d 1245, 1255,1257 (N.J. 1999) (discussing increased importance of and near universal application of the doctrine).

80. Perez, 734 A.2d at 1255 (recounting the prior norm of medical practice where patients somewhat blindly followed a physician's advice).

81. See West Virginia ex rel. Johnson \& Johnson Corp. v. Karl, 647 S.E.2d 899, 910 (W. Va. 2007) (quoting Perez, 734 A.2d at 1257). 
tice of medicine have altered the patient-physician relationship as to call into question the justifications for the LID. Managed care, ${ }^{82}$ the provision of health insurance through employers, the increasing subspecialization of medicine, increased access to technology and easy access to medical information on the internet, among other changes, have contributed to the fact that patients do not stay with the same physicians for life. Furthermore, physician time spent in patient contact has decreased, and patients are cared for by a confusing group of unconnected doctors. In other words, numerous changes to the practice of medicine, independent of the rise of DTC advertising, affect the basis on which the LID was defined, make it more difficult for a physician to function as a true "learned intermediary," and lessen the strength of the patient-physician bond. With the weakening of this bond, patients are likely to rely more on information they have gathered themselves rather than information solely from the physician. Therefore, DTC could have more of an effect on the patient's decisions in these settings.

An exception to strict liability for product manufacturers was created for unavoidably unsafe products, such as prescription pharmaceuticals. ${ }^{83}$ This exception to strict liability seems to have been created for highly useful or necessary products, and it may not even apply to completely lifestyle drugs. For drugs covered by the unavoidably unsafe doctrine, the LID requires warning only the physician of risks of the prescription medication. ${ }^{84}$ Exceptions to the LID are based mostly on a weak or nonexistent patientphysician encounter. DTC advertising erodes the patient-physician relationship by altering expectations of the relationship, shaping discussions during patient encounters, and affecting prescribing practices, among other influences. In the presence of DTC promotion, physicians may no longer meet the criteria of a "learned intermediary," since they are not the sole source of information for the patient, and their judgment may be affected by such advertising. Changes to the health care system independent of DTC advertising weaken the reasoning for application of the LID and increase the potential influence of DTC advertising. These changes also make it more difficult for physicians to be true "learned intermediaries." When deciding how DTC advertising should affect liability of the manufacturer, all of these issues should be considered.

82. Perez, 734 A.2d at 1255 (discussing how managed care has reduced the amount of time a physician spends with a patient, leaving them unable to adequately warn the patient about the drug).

83. See RESTATEMENT (SECOND) OF TORTS, $\S 402 \mathrm{~A} \mathrm{cmt.} \mathrm{k} \mathrm{(1977).}$

84. See McPheron v. Searle Lab., Inc., 888 F.2d 31 (5th Cir. 1989) (stating that those courts who have adopted comment $\mathrm{k}$ to Section 402A of the Restatement (Second) of Torts have required that proper warnings regarding "unavoidably unsafe" medications be given only to the prescribing physician). 


\section{DRUG PROMOTION TO THE PHYSICIAN PROVIDES FURTHER SUPPORT FOR A GENERAL OR CASE-BY-CASE EXCEPTION TO THE LID ${ }^{85}$}

Through the LID, physicians buffer the pharmaceutical company from liability for drug promotion to the consumer. However, pharmaceutical companies will also promote their products to physicians. Such direct-tophysician marketing allows pharmaceutical companies to exert influence over the physician who already bears the burden of DTC marketing liability. Not only is it unfair for the doctor to bear liability for the entity which influences him or her through the subversive effects of advertising, but advertising directly to the physician, like DTC advertising, intrudes into the patient-physician relationship. The patient-physician relationship is a recognized fiduciary relationship. ${ }^{86}$ Fiduciary relationships are held with high regard, and they are consequently accompanied by weighty responsibilities and protected legally from invasion or demise due to outside influences. ${ }^{87}$ Given that fiduciary relationships are protected legally, the same pharmaceutical company that influences the interaction and outcomes of the patient-physician relationship by advertising to both patients and physicians should not be protected from liability. The effect of DTC advertising on both patient and physician was explored in the previous section. This section highlights the effects of direct-to-physician advertising on the patientphysician relationship. This section further shows that it is good policy, with respect to both fairness and the desire to protect fiduciary relationships, to hold drug manufacturers that promote their medications to physicians and patients liable for such promotion.

Not only is it good policy to not allow pharmaceutical manufacturers to be insulated from liability with the LID, but also, like DTC advertising, the effects of direct-to-physician marketing make the LID inapplicable. A physician who has been influenced by direct-to-physician drug promotion no longer meets the criteria of a "learned intermediary." The data presented

85. A full exploration of the effects of drug promotion directly to physicians is beyond the scope of this article. Instead, sufficient data is presented to show how direct-to-physician advertising impedes a physician from functioning as a "learned intermediary".

86. See David Orentlicher, Health Care Reform and the Patient-Physician Relationship, 5 HEALTH MATRIX 141, 147 (1995) (noting that the patient-physician relationship has traditionally "been viewed as a fiduciary relationship in which the physician owes the patient a fundamental duty to place the patient's interests first, above not only the physician's personal interests but also the interests of other patients."); see also Petrillo v. Syntex Laboratories, Inc., 499 N.E.2d 952, 956-57 (Ill. App. Ct. 1986) (noting that public policy favors the fiduciary relationship between a patient and physician, as reflected in the "promulgated code of ethics adopted by the medical profession and ... the fiduciary relationship, recognized by courts in Illinois as well as courts throughout the United States .....").

87. See Marc A. Rodwin, Strains in the Fiduciary Metaphor: Divided Physician Loyalties and Obligations in a Changing Health Care System, 21 AM. J. L. \& MED. 241, 248 (1995) (noting that " $[t]$ raditional fiduciaries are held accountable by federal or state statutes, by courts, and by regulatory agencies."); see also Petrillo, 499 N.E.2d at 956-57 (finding that certain ex parte conferences with a treating physician are not permitted). 
in this section demonstrates how a physician who has been subjected to direct-to-physician advertising is no longer making independent medical judgments.

Direct-to-physician advertising is prevalent and successful. Although pharmaceutical companies have increased the amount spent on DTC advertising at a faster rate than that spent on direct-to-physician promotion, more money is still spent each year on advertising to the physician rather than to the general public. In $2005, \$ 7.2$ billion was spent promoting pharmaceuticals to physicians. ${ }^{88}$ Direct-to-physician advertising can take many forms, including in-person visits with drug representatives and advertisements in professional journals. Drug representatives are employees of the pharmaceutical company who provide doctors with information about the company's drugs, samples, and gifts. As of 2005, there was one drug representative per six physicians in the United States, ${ }^{89}$ and physicians were found to "me[e]t with pharmaceutical representatives about 4 times a month.,"90

While drug companies are not the sole source of information about medications for physicians, they do serve as a convenient and common source of information about medications, particularly new medications. Obviously, a pharmaceutical manufacturer will present research that demonstrates the efficacies and benefits of their medications. Drug companies, in a very practical way, not only provide information that becomes the knowledge base on which prescriptions are written, but also, by deciding which information to present and how to present it, they can shape a physician's perspective about certain medications. As might be expected, a review article found that pharmaceutical promotion to physicians had a negative effect on knowledge about the promoted medication. ${ }^{91}$ The same article reported "an . . . association between meetings with pharmaceutical representatives and formulary addition requests," and found an effect on prescriptions (e.g., "prescribing cost, nonrational prescribing, awareness, preference and rapid prescribing of new drugs, and decreased prescribing of generic drugs."). ${ }^{92}$ In other words, physicians are not making independent

88. GAO-07-54, supra note 4, at 5 .

89. Adriane Fugh-Berman \& Shahram Ahari, Following the Script: How Drug Reps Make Friends and Influence Doctors, PLOS MED., 0624 (Apr. 24, 2007), http://www. plosmedicine.org/article/info\%3Adoi\%2F10.1371\%2Fjournal.pmed.0040150.

90. Ashley Wazana, Physicians and the Pharmaceutical Industry: Is a Gift Ever Just a Gift?, 283 JAMA 373, 375 (2000).

91. Id. at 378 (stating that interactions with the pharmaceutical industry have been associated with an "inability to identify wrong claims about medication").

92. Id. at 375; see also What Impact Does Pharmaceutical Promotion Have on Behavior?, DRUG PROMOTION DATABASE (June 2, 2003), http://www.drugpromo.info/readreviews.asp?id=4 (stating, "together these studies provide convincing evidence that doctors who regard promotion more highly, and report relying on it more as a source of information about drugs, prescribe more drugs, prescribe less rationally, and prescribe new drugs earlier than other doctors" and discussing a study that "found that doctors who interacted with a 
treatment decisions based on unbiased information. Through the subtle effects of drug promotion, pharmaceutical companies affect the likelihood of prescribing certain medications and directly affect the outcome of patient encounters.

Given the psychological effects of advertising, the influence of directto-physician and DTC advertising may be more invasive into the patientphysician relationship than expected. ${ }^{93}$ For instance:

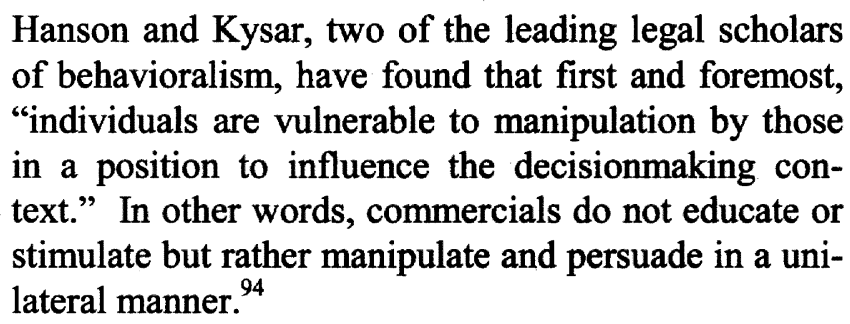

One author cited that fifty-seven percent of physician-directed advertising does not have educational value, ${ }^{95}$ and the purpose of such advertising is merely to increase prescription sales through means other than scientific data demonstrating the benefits of a particular medication. "Gifts create both expectation and obligation"96 and thus, it can be said that physicians are also subject to the effects of gifting from pharmaceutical representatives. However, gifts have also been found to be "correlated with the belief that pharmaceutical representatives have no impact on prescribing behavior."97 Unfortunately, those doctors "influenced by pharmaceutical marketing nonetheless believe that their information is scientific and unbiased." 98 Additionally, pharmaceutical representatives are privy to a physician's prescribing practices, and can therefore tailor their message about different drugs to the practices of that physician, making the sales pitch more effective than mass marketing alone. ${ }^{99}$ The psychological conse-

company were between 9 and 21 times more likely than other doctors to have requested that a drug made by that company be added to the formulary.").

93. Richardson, supra note 12, at 1037 (stating of the Perez decision, "Section III is arguably the most important part of Perez because it recognizes that DTC advertising has a significant psychological impact on consumers that changes the relationship between the physician and patient. ... It is these changes that warp the function of the LID from protecting important physician prerogatives to simply protecting manufacturers.").

94. Id. at 1041 .

95. Id. at 1043 .

96. Fugh-Berman \& Ahari, supra note 89 , at 0621.

97. Wazana, supra note 90 , at 375-6.

98. Howard Brody, The Company We Keep: Why Physicians Should Refuse to See Pharmaceutical Representatives, 3 ANNALS OF FAM. MED. 82, 83 (2005); see also Wazana, supra note 90 , at 375 (finding that physicians "believe that representatives provide accurate information about their drugs and are equivocal in their beliefs that representatives could provide accurate information on established or alternative drugs").

99. Fugh-Berman \& Ahari, supra note 89, at 0623; IMS Health Corp. v. Rowe, 532 F.Supp.2d 153, 158 (D. Me 2008). 
quences of DTC and direct-to-physician advertising are intended to be subtle, and therefore harder to protect against. ${ }^{100}$ However, because the advertising affects how one thinks, feels, and interacts with respect to a certain diagnosis or drug, DTC and direct-to-physician advertising have a significant effect on the patient-physician relationship and the independence of a physician's medical judgment.

As the previous section demonstrated, even DTC advertising can affect a doctor's treatment decisions when coupled with the effects of directto-physician advertising. Whether the physician's prescribing decisions are independent should be called into question when drug promotion has occurred. These concerns are multiplied by the fact that the same drugs are frequently and simultaneously promoted to both patient and physician. ${ }^{101}$ When a physician does not make an independent medical judgment because he or she has been influenced by DTC or direct-to-physician advertising, the physician no longer meets the definition of a "learned intermediary," and the LID should not be applied. This logic could be used to justify a general exception to the LID for either DTC advertising or direct-tophysician promotion. This logic could also be used on a case-by-case basis to find individual exceptions to the LID. Besides calling into the question the presence of a "learned intermediary," drug promotion intrudes into the patient-physician fiduciary relationship by influencing both parties to that relationship. Such an intrusion should be accompanied by an appropriate legal response in order to protect that fiduciary relationship. Lastly, it is fundamentally unfair for physicians who no longer meet the criteria of a "learned intermediary" because of drug manufacturer influence to bear that manufacturer's liability for drug promotion. Pharmaceutical manufacturers should be held liable for their intrusions into patient-physician relationships, rather than being sheltered from liability under the LID.

\section{DTC ADVERTISING CREATES A NEAR OR ACTUAL FIDUCIARY RELATIONSHIP BETWEEN PATIENT AND PHARMACEUTICAL MANUFACTURER}

Fiduciary relationships are defined by the fact that one party is to act for the benefit of the other. To ensure such selfless action, the law imposes certain strict duties upon the fiduciary. Further, fiduciary relationships do not have to be formally established. ${ }^{102}$ Case law and scholarship elaborate

100. Even those physicians who attempt to limit or eliminate pharmaceutical industry influence in their practice may have difficulty. The industry now funds a large portion of research, and such funding has been correlated with the publication of those studies with positive findings. What Impact Does Pharmaceutical Promotion Have on Behavior?, DRUG PROMOTION DATABASE (June 2, 2003), http://www.drugpromo.info/read-reviews.asp?id=4.

101. GAO-07-54, supra note 4, at 14.

102. Fiduciary Relationship, LAW.COM DICTIONARY, http://dictionary.law.com/Default. 
on what may be required to create a fiduciary relationship, as well as the relationship's accompanying legal responsibilities.

As an example, a Minnesota court recently stated rather simply that "[f]iduciary relationships arise when one person trusts and confides in another who has superior knowledge and authority. A court may find the necessary relationship in light of 'moral, social, domestic, or merely personal factors." 103 A 2008 Seventh Circuit decision went so far as to state a presumption for fiduciary relationships when "one party has a superior position and sustains a substantial advantage over the other."104 The inherent relationship between pharmaceutical companies and patients meets the standard established by the two cases above. First, there is little doubt that drug companies possess superior knowledge of particular medications or conditions as compared to the average consumer of their drugs. Second, the superiority of the drug companies may be heightened by the increased vulnerability experienced by individuals with certain ailments when viewing pharmaceutical advertisements. ${ }^{105}$ As discussed in the previous sections, advertising is persuasive and subtle, allowing the drug companies to gain authority or influence over the consumers. In addition, some pharmaceutical companies advertise not only their products, but also the company itself. For instance, companies may highlight the moral, responsible way in which they perform vital social functions. ${ }^{106}$ Such advertising, in conjunction with online quizzes or applications for financial assistance, create a sense of trust and confidence in the drug manufacturer. Therefore, DTC advertising may create a fiduciary relationship through the fiduciary standards discussed by these two courts. However, other courts have outlined more specific requirements to establish certain fiduciary relationships. For the attorney-client and doctor-patient relationships, it appears that these more specific requirements frequently include the giving of individualized advice and reasonable reliance on that advice.

The first step in forming a fiduciary relationship usually falls to the beneficiary - he or she seeks the advice or services of the prospective fiduciary, ${ }^{107}$ with some courts noting that the services should be sought because

aspx? selected $=745 \&$ bold $=\% 7 \mathrm{C} \% 7 \mathrm{C} \% 7 \mathrm{C} \% 7 \mathrm{C}$ (last visited April 6, 2010).

103. Swenson v. Bender, 764 N.W.2d 596, 601 (Minn. Ct. App. 2009).

104. Interactive Intelligence, Inc. v. Keycorp, 546 F.3d 897, 900 (7th Cir. 2008).

105. Hoopes v. Hammargren, 725 P.2d 238, 242 (Nev. 1986) (expressing vulnerability of patients with illness).

106. See, e.g., Our Company, ASTRAZENECA US, http://www.astrazeneca-us.com/ about-astrazeneca-us/our-company/ (last visited June 15, 2010) (stating "not only are we working to discover the next new medicine, but we're also working to help make healthcare a more meaningful, more personal experience for patients"); Corporate Social Responsibility, PFIZER, http://www.pfizer.com/responsibility/ (last visited June 15, 2010) (advertising "[d]oing business responsibly" and stating "we are striving to adapt to the evolving needs of society and contribute to the overall health and wellness of our world").

107. See Catherine J. Lanctot, Attorney-Client Relationships in Cyberspace: The Peril and the Promise, 49 DuKE L. J. 147, 169 (1999); Douglas K. Schnell, Don't Just Hit Send: Unsolicited E-mail and the Attorney-Client Relationship, 17 HARVARD J. L. \& TECH. 533, 
of the fiduciary's expertise. ${ }^{108}$ There must be some voluntary response on the part of the fiduciary in order to create the relationship. ${ }^{109}$ However, the voluntary response could be minimal; the Virginia Supreme Court has found that a physician-patient relationship can be formed "from whatever circumstances evince the physician's consent to act for the patient's medical benefit." 110

In the case of DTC advertising, the would-be beneficiary cannot seek the advice of the pharmaceutical manufacturer through personal consultation since these advertised medications have to be obtained through a physician. However, an individual could be seen as seeking the advice of the pharmaceutical company in one of two ways: by locating the company's website and reading the information or responding to any questions on the website; or by reading or hearing advertisements in any format and processing them sufficiently so as to use the information for a prescription request. As for the voluntary response on the part of the fiduciary, advice given through advertisements could "evince . . . consent to act for the patient's medical benefit[;]"111 after all, advice is not deserving of that name if it is not meant for the benefit of the recipient. Yet, the advice presented in advertisements predates any request, and therefore, is not a response. However, one state's professional responsibility committee concluded that at least certain fiduciary duties can be acquired when a lawyer receives unsolicited e-mails prompted by a website. ${ }^{12}$ In other words, the consent of the fiduciary may be preexisting if such consent is related to the "seeking" behavior of the beneficiary. If pharmaceutical advertising prompts an individual to request a medication, take an online quiz, print out coupons for free trials of a prescription medication, or any number of other behaviors, a court could rationally find that the beneficiary had sought the advice of the fiduciary and the fiduciary had consented to the relationship.

Varying levels of personalization and specification of the advice are required in order to form a fiduciary relationship. In attorney-client relationships, general legal advice is considered insufficient to consummate such a relationship, but advice in response to specific facts discussed by a

538, 540 (2004) (citing Kurtenbach v. TeKippe, 260 N.W.2d 53 (Iowa 1977) and RESTATEMENT (THIRD) OF THE LAW GOVERNING LAWYERS $\$ 14 \mathrm{cmt} . \mathrm{c}(2000)$ ).

108. Lanctot, supra note 107, at 175 (quoting from Foulke v. Knuck, 784 P.2d 723 (Ariz. Ct. App. 1989)).

109. However, one author has concluded that fiduciary relationships could be formed through unsolicited e-mails from the beneficiaries if such e-mails were prompted by the fiduciary's website. Schnell, supra note 107 , at 551 . This view could be particularly important for pharmaceuticals, as each advertised drug frequently has its own website.

110. Fruiterman v. Granata, 668 S.E.2d 127, 136-37 (Va. 2008) (quoting Lownsbury v. VanBuren, 762 N.E.2d 354, 360 (2002)).

111. Id.

112. Schnell, supra note 107, at 549-51 (discussing State Bar of Arizona Committee on Rules of Professional Conduct Opinion 02-04 on unsolicited e-mails and the duty of confidentiality). 
client generally tends to create a fiduciary duty. ${ }^{113}$ In finding that a doctorpatient relationship did not exist, one court found there was no individual or specific interaction between the physician and the patient. ${ }^{114}$ Likewise, in finding that a duty to the patient did exist, a Maryland court noted that the physician had advised the patient regarding his health condition. ${ }^{115}$ Calling for fewer requirements to apply a duty, the Kentucky Supreme Court found a physician owed a duty to an individual because the physician had directed the patient's family in the emergency room several times; this direction was not related to specifics of the patient's health status at all. ${ }^{116}$

How specific and individualized the advice must be to form a fiduciary relationship might depend on the subject matter of the relationship. When the subject matter concerns the more vulnerable party's health, the advice might not have to be specific to the individual's health status if it is directed to the individual or others responsible for the individual's health. It could be argued that the contrary should also be true. That is, less individualization is required if the advice is health related. Advice found in DTC advertising is health related, but has varying levels of individualization. Online surveys with feedback may be both directed at the individual and include advice specific to an individual's health status, thus satisfying either criteria. Commercials and magazine or newspaper advertisements, though seen and heard by the general public, are directed at a group of individuals with certain problems or concerns; ${ }^{117}$ in other words, there is some level of individualization in the recipient of the message. Given that the advice contained within an advertisement can be unambiguous in listing symptoms and suggesting treatments based on these symptoms, ${ }^{118}$ (i.e., advertisements frequently offer specific health advice) and always has some

113. See Lanctot, supra note 107 , at $160-61$.

114. Jenkins v. Best, 250 S.W.3d 680, 688 (Ky. Ct. App. 2007) (stating "Dr. Best never saw or examined Jenkins, never spoke to her or consulted or gave her advice. Dr. Best never reviewed Jenkins' chart or made any entry in it. Dr. Best never consulted with Dr. Farmer while Jenkins was under his care. Dr. Best never issued either medical or nonmedical orders. Nor did she render any opinions or recommendations. She did not participate in Jenkins' diagnosis or treatment. ... In summary, Dr. Best did nothing that constitutes an undertaking to render medical care to Jenkins.").

115. Hoover v. Williamson, 203 A.2d 861,864 (Md. 1964) ("The allegations amount to more than that the doctor kept silent after review of the X-ray revelations and the findings of the consultant. The charge of affirmative misrepresentation was coupled with the charge of concealment of the consultant's recommendations and, under the circumstances, made the concealment as much a breach of duty as the affirmative misrepresentation.").

116. Noble v. Sartori, 799 S.W.2d 8, 9 (Ky. 1990).

117. See, e.g., Boehringer Ingelheim/Pfizer, Advertisement, Once-Daily Spiriva HandiHaler, FAMILY CIRCLE, Oct. 2010, at 75-76 (directing their message to individuals with COPD for whom rescue inhalers are not sufficient).

118. See, e.g., id. (stating that for individuals with COPD, "rescue inhalers alone may not be enough" and suggesting the reader talk to their "doctor about Spiriva, because it: Is the only once-daily, inhaled maintenance prescription treatment for both forms of COPD[; s]ignificantly improves lung function by keeping airways open[; h]elps you breathe better for a full 24 hours[; and i]s not a steroid.") (alteration in original). 
level of individualization, a court should find sufficient personalization in various forms of DTC advertising to apply at least some fiduciary duties to the pharmaceutical advertiser.

While there is not a clear answer as to how individualized and specific the advice must be to form a fiduciary relationship, there is consensus on the mode of communication between the two parties. Any mode of communication appears to be sufficient, and face-to-face contact is not required to form a fiduciary relationship. Advice given over the telephone, ${ }^{119}$ through e-mail, ${ }^{120}$ or over the internet may all be sufficient. ${ }^{121}$ If internet communication satisfies the requirements for forming a fiduciary relationship, other modes of advertising medications directly to the consumer could be used to form a fiduciary relationship. The advice offered by pharmaceutical companies in internet advertisements is usually available to the general public and further contact requires action on the part of the beneficiary. Similarly, the information found in commercials or print advertisements can be read or heard by anyone and further contact must be initiated by the beneficiary.

The last step in forming a fiduciary relationship is reasonable reliance on such advice. ${ }^{122}$ One author, in reviewing attorney-client relationships, found courts are very lenient in declaring the client's reliance to be reasonable. ${ }^{123}$ Although lenient, another author concluded that it must be objectively reasonable to rely on the advice. ${ }^{124}$ The more specific and particular the advice, the more reasonable the reliance. ${ }^{125}$ With respect to DTC advertising, it could be argued that consumers should recognize advertising for what it is, making reliance unreasonable. On the other hand, the persuasive effects of advertising, the individualized advice found in drug promotion, and the advertiser's superior knowledge should be considered when determining reasonable reliance. Given that DTC advertising has been shown to increase pharmaceutical sales, it seems clear that a large amount of the population relies in part on advice within advertisements. Because reliance on

119. Alissa R. Spielberg, Online without a Net: Physician-Patient Communication by Electronic Mail, 25 AM. J. L. \& MED. 267, 292 (1999).

120. See id. at 292-93.

121. See, e.g., Reynoso v. Neary, 315 B.R. 544 (B.A.P. 9th Cir. 2004) (finding that individuals who created and operated website that completed bankruptcy petitions amounted to the unauthorized practice of law).

122. See Lanctot, supra note 107 , at $160-61$ ("[C]ourts traditionally have been willing to infer attorney-client relationships when lawyers give specific legal advice to laypeople under circumstances in which it would be reasonable for them to rely on the advice.").

123. Id. at 184 (stating "courts are willing to take a broad view of reasonableness").

124. Schnell, supra note 107 , at 540 (stating "the belief must be objectively reasonable under the circumstances").

125. See Lanctot, supra note 107, at 183 (stating "it is reasonable for a putative client to rely on advice that is specifically tailored to his particular request"); Schnell, supra note 107, at 543, (" $[1] \mathrm{f}$ the lawyer is responding to a specific question or offering advice on specific facts, she is much closer to an implied attorney-client relationship because of the potential for reasonable reliance than if she is just answering a general question about the law."). 
information in drug advertisements is common, it should be found reasonable in many circumstances. ${ }^{126}$

Even if advice given in drug advertisements is not found to create a fiduciary relationship, once the advice is given, the manufacturer clearly acquires certain duties. In other words, one does not have to be held to the full set of fiduciary obligations, and all fiduciary obligations may not make sense in a pharmaceutical manufacturer-consumer relationship; rather, certain duties can and should be applied based on the circumstances. ${ }^{127}$ One court stated that there was no doubt that the giver of advice, even gratuitous advice, has a duty of due care. ${ }^{128}$ Further, the more specific and complex knowledge possessed by an individual or entity, the higher the duty to which they will be held. ${ }^{129}$ In arguing that the LID should not apply when DTC advertising has occurred, one author concluded that interactive websites advertising prescription drugs allow the pharmaceutical company to "advertise[] itself into the physician's role." "30 This characterization was based on the fact that the drug companies encourage consumers to discuss the drug on line and present information and advice about the drug and related condition on its website. ${ }^{131}$ It is not only websites that offer such intricate information, but also other forms of advertising. Because of the greater knowledge possessed by the drug manufacturer and the advice presented in advertisements, the pharmaceutical manufacturer who advertises should fulfill at least some fiduciary duties. This is particularly true when the advice revolves around something as sacred as one's health and the product is both esoteric and potentially damaging to one's wellbeing.

\section{CONCLUSION}

Both DTC advertising and changes to the health care system have eroded the rationale for the LID. Physicians are also the target of aggressive pharmaceutical marketing. A physician is no longer a "learned inter-

126. If liability for the content of drug advertisements becomes more prevalent, it is reasonable to expect use of disclaimers in advertisements. Sometimes a disclaimer can make reliance unreasonable. On the other hand, people may be reluctant to accept a disclaimer, especially if the beneficiary is not represented, unsophisticated, or when there is no affirmative assent to the disclaimer. See Schnell, supra note 107, at 557, 559-60 (concerning disclaimers in an attorney-patient relationship).

127. See Hoover v. Williamson, 203 A.2d 861 (Md. 1964) (finding no fiduciary relationship (doctor-patient relationship), but declaring that if the doctor acts gratuitously there may be some duty to act carefully).

128. Id. at 863 ("[O]ne who assumes to act even though gratuitously, may thereby become subject to the duty of acting carefully.").

129. See Stanley v. McCarver, 92 P.3d 849, 854 (Ariz. 2004) ("The standard of care imposes on those with special skills or training . . . the higher obligation to act in light of that skill, training, or knowledge .....").

130. Foreman, supra note 79 , at 112 (alteration in original).

131. Id. 
mediary" when drug promotion shapes his or her knowledge of medications, influences prescribing behavior, and alters a physician's interpretation of patient symptoms. Therefore, direct-to-physician marketing further weakens the rationale for application of the LID. In addition, marketing to the physician, like DTC advertising, intrudes into the patient-physician relationship. Pharmaceutical companies should not be insulated from liability for advertising when such advertising influences the legally recognized fiduciary relationship of patient-physician through subversive, but real, manipulation of both parties to that relationship. Given that drug promotion weakens the patient-physician relationship and makes it difficult for a physician to function as a true "learned intermediary," courts should eliminate the LID and impose joint liability on the part of the pharmaceutical manufacturer and the physician in DTC advertising cases. ${ }^{132}$ Should a general exception to the LID for DTC advertising not be accepted, courts should look to the criteria for a learned intermediary on a case-by-case basis.

Given the presence of advice on matters relating to personal health in DTC advertising, such advertising should create fiduciary duties, or perhaps even fiduciary relationships, between drug consumer and drug manufacturer. To determine the types of duties and whether an actual fiduciary relationship exists, courts should analyze the content and mode of advertising, paying special consideration to the level of individualization of the advice for the drug or condition. ${ }^{133}$

Imposing the LID when DTC advertising has occurred provides the pharmaceutical manufacturers full license to advise on and impact a patient's health with impunity, all while undermining the patient-physician relationship. The pharmaceutical company is allowed to reap the financial benefits of DTC advertising while physicians and patients are left to bear both the financial and personal burdens of such actions. ${ }^{134}$ Maintaining the current liability situation is untenable and must change. When faced with failure to warn cases involving DTC advertising, courts should acknowledge the need for an exception to the LID or, at the very least, properly investigate whether the physician actually functioned as a learned intermediary in the case at hand. The possibility of imposing fiduciary obligations on the pharmaceutical company that advertises should be explored.

132. See Perez v. Wyeth Laboratories Inc., 734 A.2d 1245, 1262-63 (N.J. 1999) (stating, "In the case of direct marketing of drugs, we believe that neither the physician nor the manufacturer should be entirely relieved of their respective duties to warn.").

133. See Foreman, supra note 79 , at 117 (suggesting a case by case approach to determine whether the LID should be applied).

134. See West Virginia ex rel. Johnson \& Johnson Corp. v. Karl, 647 S.E.2d 899, 913 (W.Va. 2007) ("[B]ecause it is the prescription drug manufacturers who benefit financially from the sales of prescription drugs and possess the knowledge regarding potential harms, and the ultimate consumers who bear the significant health risks of using those drugs, it is not unreasonable that prescription drug manufacturers should provide appropriate warnings to the ultimate users of their products."). 
